\title{
An air mass-based approach to regional GCM validation
}

\author{
Mark D. Schwartz* \\ Department of Geography, University of Wisconsin-Milwaukee, Milwaukee, Wisconsin 53201, USA
}

\begin{abstract}
Current Global Climate Models (GCMs) lack the resolution and physics to provide detailed assessments of changes on the regional scale, where many important societal impacts occur. Model improvement efforts can be facilitated by a systematic characterization of regional control-run $\left(1 \times \mathrm{CO}_{2}\right)$ values. Synoptic-scale analyses offer appropriate methods for this task, such as air mass analysis. Companison of air mass types derived from a GCM control run and observed data provides an assessment of GCM circulation, near-surface temperature, and moisture patterns. In this study, 10 simulated years of control-run data from the GENESIS Version $1.02 \mathrm{GCM}$ are evaluated in light of 1961-1990 observed data from the North Central United States (NCUS). The GCM simulation fares much better in recreating a proper mix of synoptic patterns in seasons where 1 air mass type is not overwhelmingly dominant. That is, the prominence of Continental air in winter, and Tropical air in summer are overemphasized, while spring and autumn seasonal distributions are more accurate. The circulation patterns associated with each air mass category are simulated rather well in most cases by the GCM. Air mass temperatures and dew points, however, are not well represented in the non-winter seasons. Cold air masses tend to be too warm, and warm air masses too cold in spring and autumn. In summer, all air masses are too warm. While the seasonal GCM performance in the NCUS is promising, these results suggest that there may be substantial differences between the GENESIS GCM Version 1.02 control run and observed climate data at the daily time scale.
\end{abstract}

KEY WORDS: Air mass - Global Climate Model - Regional validation

\section{INTRODUCTION}

Global Climate Models (GCMs) are fundamental tools for examining potential climate change. Unfortunately, current GCMs lack the resolution and detailed physics needed to provide reliable assessments of changes on the regional (synoptic) scale, where many important societal impacts occur (Schlesinger \& Mitchell 1987. Grotch \& MacCracken 1991). Sustained and multifaceted efforts will be needed to ultimately improve model performance at these resolutions. Such assessments should begin by addressing deviations of model mid-tropospheric circulation patterns from observed data. Circulation features, generated by embedded Atmospheric General Circulation Models (AGCMs), are essential to overall GCM performance and typically the most accurate part of a simulation (Hewitson \& Crane

\footnotetext{
•E-mail: mds@csd.uwm.edu
}

1992, Hewitson 1994). Many methods exist to diagnose regional GCM performance, yet synoptic-scale analyses (such as air mass analysis) are especially appropriate.

The regional frequency and distribution of air masses are a direct result of synoptic and larger-scale circulation patterns. Thus, comparison of the air mass types within a GCM control-run simulation to observed data provides a first order assessment of GCM circulation, near-surface temperature, and moisture patterns-inasmuch as air mass distributions can be systematically delimited and back-linked to midtropospheric $(500 \mathrm{hPa})$ flow patterns (Schwartz \& Skeeter 1994). Similar approaches have proved useful for characterizing climate change and its effects (Kalkstein et al. 1990, Brinkmann 1993, Frakes \& Yarnal 1995, Schwartz 1995). Resulting GCM assessments are more detailed than those possible using undifferentiated monthly averages - the typical values calculated to assess GCM control-run simulations-yet still of similar computational complexity (Schneider \& Rosen- 
berg 1989, Thompson \& Pollard 1995). Air mass analysis also integrates temperature and moisture variables, providing a multi-variable appraisal. Further, if air mass characteristics are identified and compared at the $850 \mathrm{hPa}$ level, rather than at the surface, the resolution of GCM simulations is less restrictive for the analysis. Temperature and moisture properties are more conservative at levels above the surface, and thus coarse GCM spatial resolution does not automatically preclude its accuracy (Schwartz 1995).

This paper will demonstrate how a comparison of air mass characteristics between observed data and a GCM control run can facilitate assessment of regional climate veracity within the simulation. Further, the results provide clues to fundamental differences in the overlying GCM versus observed circulation that could be beneficial in diagnosing GCM behavior, and may suggest areas of future model improvements. In this study, the seasonal characteristics of air masses in the North Central United States (NCUS), as derived from observed data and GENESIS Version 1.02 GCM output, will be compared (Thompson \& Pollard 1995). This region has the greatest air mass diversity in North America and provides a 'window' to mid-tropospheric flow changes taking place over the entire North American continent (Schwartz 1991, Schwartz \& Skeeter 1994).

\section{STUDY AREA, DATA BASES, AND METHODOLOGY}

\subsection{Study area}

The well-documented air mass contrast of the NCUS (Fig. 1) makes it an ideal study area for synoptic-scale

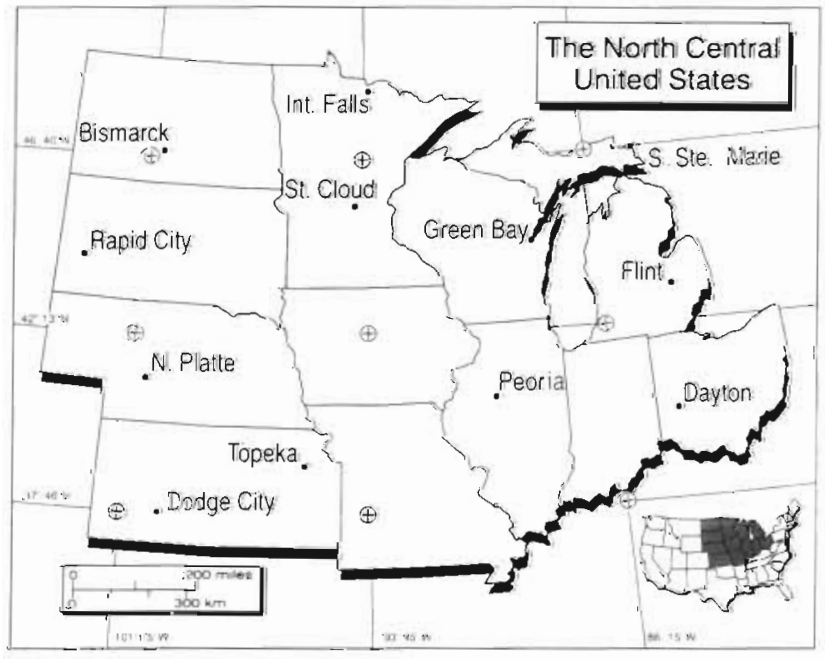

Fig. 1 Study area with observed data station locations and GENESIS GCM grid point locations ( $\oplus$ ) research (Bryson 1966, Schwartz 1991). The Integrated Method Air Mass Classification Scheme developed by Schwartz (1991), and further validated by Schwartz \& Skeeter (1994), will provide designations of GCMderived and observed air mass types and characteristics within the study area. Air masses are identified within representative months of each season (January, April, July, and October) based on daily 1200 UTC (Universal Time Coordinates) $850 \mathrm{hPa}$ temperatures and dew points (Fig. 2; see Appendix 1 for a brief description of the classification scheme).

\subsection{GCM data}

A total of 10 simulated years of $850 \mathrm{hPa}$ daily average temperatures and specific humidities (derived by interpolation between 2 vertical model levels) from a GENESIS Version 1.02 GCM control run (see Appendix 2 for a brief description) comprised the basic GCM database. Values for the months of January, April, July, and October at 9 grid points which fell within or near

\section{Air-Mass Criteria}

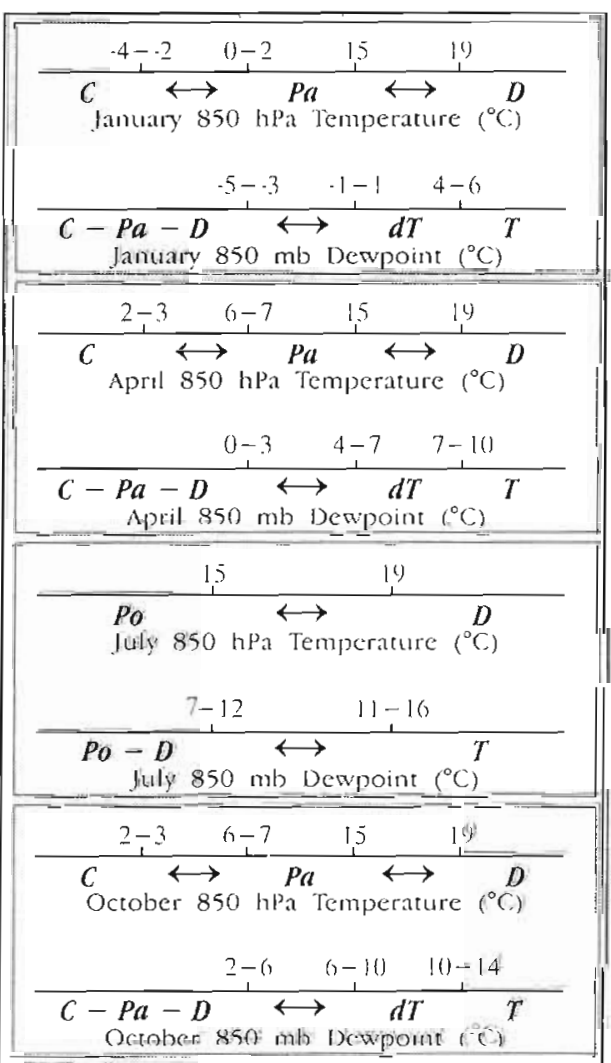

Fig. 2. Integrated method air mass classification scheme $(C$ Continental $P_{a}$ : Pacific; $D$ : Dry Tropical; $d T$ : dilute Tropical; T: Tropical; Po: Polar. From Schwartz (1995), used with publisher's permission 
the NCUS were selected for further analysis (Fig. 1). The following 3 -stage procedure was employed to process these data into values comparable to daily 1200 UTC temperatures and dew points (required as input for the integrated method air mass classifier).

First, averages of the 0000 UTC-1200 UTC temperature difference by station and month were obtained for available real observation stations in the NCUS (analysis performed by A. Oort based on the 1980-1989 period, pers. comm.). This difference approximates the diurnal range in the study area. Due to the conservative nature of the $850 \mathrm{hPa}$ layer, diurnal temperature ranges at this level are quite small, typically $1^{\circ} \mathrm{C}$ or less (0.20 in January, 0.82 in April, 0.88 in July, and $0.36^{\circ} \mathrm{C}$ in October). Secondly, all station difference values were averaged for each month, producing proxy NCUS-wide $850 \mathrm{hPa}$ diurnal ranges. One-half of the appropriate observed monthly diurnal range was subtracted from each GCM daily average temperature at all 9 grid points in order to generate proxy 1200 UTC values (assumed to be near the minimum for the day). Lastly, the derived daily 1200 UTC temperature values and average daily specific humidity values were used to calculate daily 1200 UTC dew points (Schlatter \& Baker 1981), assuming a constant daily moisture content.

\subsection{Observed data}

The next step of the methodology was to develop an observed data set. This process was simplified by the conservative nature of upper-air atmospheric variables, as reporting stations are more widely spaced than surface stations and thus have about the same spatial density as the GCM grid points. The conservative nature of the $850 \mathrm{hPa}$ level has a further implication for the analysis: air mass types and transitions in the observed data are more like those which can be recognized in the limited spatial resolution of the GCM simulation. Thus, air mass characteristics at this level are more appropriate for comparison to GCM output than surface values. Twelve stations, with daily 1200 UTC $850 \mathrm{hPa}$ temperature and dew point data available for the months of January, April, July, and October over the entire 1961-1990 period, were selected as representative of the current observed climate in the NCUS (Fig. 1).

\subsection{Air mass classification}

The completed daily $850 \mathrm{hPa}$ temperature-dew point databases (observed and GCM) were both processed through the integrated method air mass classification scheme (Schwartz 1991). The technique yielded daily air mass types during the months of January, April, July, and October for each of the 12 observed data stations and 9 GCM grid points.

\subsection{GCM-observed comparisons}

Monthly average air mass frequencies for the 12 observed stations (1961-1990 period) were interpolated to the 9 GCM grid point locations to allow direct comparison of GCM-observed spatial patterns. Similarities between the GCM (average of 10 simulated years) and observed patterns were assessed by testing the point-to-point correlation, row-to-row (northsouth) difference correlation, and column-to-column (east-west) difference correlation between matching air mass types in each season.

Given the coarse spatial resolution within a GCM simulation, comparing the 2 data sets' inter-NCUS air mass distributions may be too stringent a way to evaluate GCM performance. Therefore, study area-wide composites of daily station (grid point for GCM) values within each database were produced for all further comparison tests. These composites included every daily station (grid point for GCM) value over the study period that was classed in each respective air mass category. Stations or grid points for a particular day need not all fall into the same air mass category. The averages produced included monthly air mass frequency, monthly air mass $850 \mathrm{hPa}$ temperature, and monthly air mass $850 \mathrm{hPa}$ dew point for each air mass during all 4 seasons. To provide a basis for objective evaluation, corresponding values from the observed and GCM databases were subjected to paired sample $t$-tests to determine their statistical similarity. In the case of the temperatures and dew points, these averages are based directly on daily values (frequencies are monthly). Use of such 'uncorrected' daily data may violate the $t$-test assumptions, since individual days are likely serially correlated. This concern was addressed by initially averaging values within consecutive runs of 'same air mass days' before statistical analyses were performed (Brinkmann 1993).

\section{RESULTS}

\subsection{January}

The spatial distributions and magnitudes of GCMproduced and observed NCUS air masses showed several areas of agreement during January, but also notable differences. The overall (point-to-point) distributions of Continental air ( $C$, the major type, Fig. 3) 


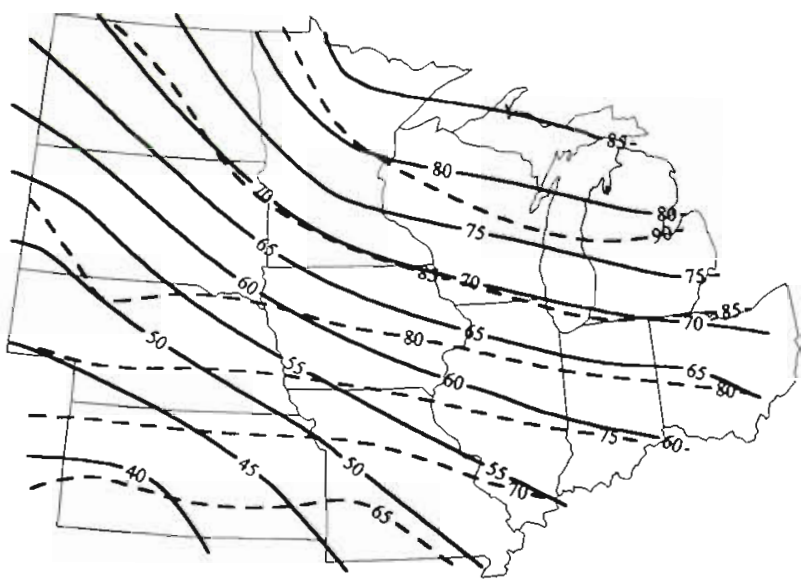

Fig. 3. January Continental air mass relative frequency comparison in the NCUS between observed data (solid lines) and GENESIS GCM-derived data (dashed lines)

and Unclassed air $(U)$ compared favorably, but the specifics of the patterns (row and column differences) were dissimilar (Table 1). $C$ air was also significantly more frequent within the GCM (Table 2). Pacific $(P a)$ air was strongly underrepresented by the GCM, especially in the southwestern portions of the study area. While the overall magnitudes of dilute Tropical $(d T)$ air were not significantly different, the GCM overrepresented this air mass in the western NCUS. Lastly, Tropical (T) air was much too infrequent in the GCM simulation, though reasonably similar to the observed spatial pattern (Table 1). In terms of temperature, the GCM was not significantly different from the observed data for $C, d T$, and $U$ air, but too cold for $P a$ air. GCM dew points were too high for $C, P a$, and $U$ air, but similar for $d T$ (Table 3; note: the GCM simulation did not include enough $T$ days to make temperature or dew point comparisons possible in this month).

\subsection{April}

In April, the GCM and observed air mass patterns showed a greater degree of agreement than in January. The spatial patterns and magnitudes of $C$ air were fairly similar, and $T$ air was a very close match (Tables 1 \& 2, Fig. 4). Once again, $P a$ air was underrepresented especially in the southwestern portions of the study area, though the
GCM simulation displayed the proper spatial orientation. $d T$ air was poorly represented in terms of magnitude, and the GCM positioned the highest relative frequency of this air mass in the southwestern NCUS, rather than the observed south-central location. $U$ air was not well simulated either in terms of magnitude or pattern. The GCM $U$ air distribution was oriented west-to-east, with lowest values in the east, while the observed distribution showed a southwest to northeast orientation, with highest values in the southwestern study area. $D$ air was not frequent enough in this month to be effectively compared. Air mass temperatures displayed significant differences for all types (Table 3). The GCM values were too high for $C$ air, and too low for all other types. Dew point values were not significantly different for $d T$ or $T$ air, but the GCM values were too high for all other types.

\subsection{July}

July air mass spatial patterns were quite similar between the observed and GCM data for all types except $U$ air (Table 1). The GCM $U$ air pattern increased toward the northwest, while the observed $U$ air distribution increased toward the west. In terms of

Table 1. Air mass spatial distributions. RMS: root mean square; $C$ : Continental; Pa: Pacific; dt: dilute Tropical ${ }_{i} T$ : Tropical; $D$ : Dry Tropical; $U$ : Unclassed; Po: Polar; NA: not applicable

\begin{tabular}{|c|c|c|c|c|}
\hline $\begin{array}{l}\text { Air mass } \\
\text { type }\end{array}$ & $\begin{array}{l}\text { Overall } \\
\text { point-to-point } \\
\text { correlation } \\
\text { (sig.) }\end{array}$ & $\begin{array}{l}\text { RMS } \\
\text { error } \\
(\%)\end{array}$ & $\begin{array}{c}\text { E-W column } \\
\text { difference } \\
\text { correlation } \\
\text { (sig.) }\end{array}$ & $\begin{array}{c}\text { N-S row } \\
\text { difference } \\
\text { correlation } \\
\text { (sig.) }\end{array}$ \\
\hline January $C$ & $0.93(0.0005)$ & 18.6 & • & - \\
\hline January $P a$ & $\because$ & 16.7 & · & • \\
\hline January $d T$ & $0.52(0.15)$ & 2.9 & · & $\cdot$ \\
\hline January $T$ & $0.75(0.02)$ & 1.1 & $0.36(0.49)$ & $0.55(0.26)$ \\
\hline January $D$ & NA & NA & NA & NA \\
\hline January $U$ & $0.91(0.001)$ & 3.8 & $\cdot$ & $-0.83(0.04)$ \\
\hline April $C$ & $0.87(0.002)$ & 10.2 & $0.53(0.28)$ & $\cdot$ \\
\hline April $\mathrm{Pa}$ & $0.80(0.01)$ & 10.9 & $0.74(0.09)$ & $0.75(0.09)$ \\
\hline April $d T$ & $0.43(0.25)$ & 8.7 & $\because$ & $0.67(0.15)$ \\
\hline April $T$ & $0.96(0.0005)$ & 4.4 & $0.96(0.003)$ & $0.81(0.05)$ \\
\hline April $D$ & NA & NA & NA & NA \\
\hline April $U$ & $0.69(0.04)$ & 8.4 & $\cdot$ & $\cdot$ \\
\hline July Po & $0.95(0.0005)$ & 20.5 & $0.55(0.25)$ & $0.56(024)$ \\
\hline July $T$ & $0.86(0.003)$ & 29.5 & $0.75(0.09)$ & $0.65(0.16)$ \\
\hline July $D$ & $0.91(0.001)$ & 8.1 & $0.96(0.002)$ & $0.85(0.03)$ \\
\hline July $U$ & $0.32(0.40)$ & 9.2 & $\cdot$ & : \\
\hline October $C$ & $0.97(0.0005)$ & 13.3 & $0.80(0.06)$ & $0.59(0.22)$ \\
\hline October $\mathrm{Pa}$ & $0.89(0.001)$ & 15.0 & $0.58(0.22)$ & $0.76(0.08)$ \\
\hline October $d T$ & $0.57(0.11)$ & 5.2 & $\cdot$ & $0.86(0.03)$ \\
\hline October $T$ & $0.97(0.0005)$ & 3.0 & $0.99(0.0005)$ & $0.85(0.03)$ \\
\hline October $D$ & NA & NA & NA & NA \\
\hline October $U$ & $0.30(0.43)$ & 9.9 & $-0.77(0.08)$ & $-0.53(0.29)$ \\
\hline
\end{tabular}


Table 2. Air mass relative frequency comparison. Abbreviations defined in Table 1

\begin{tabular}{|lccc|}
\hline Air mass & $\begin{array}{c}\text { Study area } \\
\text { type }\end{array}$ & $\begin{array}{c}\text { Study area GCM } \\
\text { observed monthly } \\
\text { monthly average } \\
\text { frequency } \\
(\%)\end{array}$ & $\begin{array}{c}\text { t-test } \\
\text { sig. level } \\
(2 \text {-tail })\end{array}$ \\
\hline January $C$ & $(\%)$ & 79.4 & $<0.001$ \\
January $P a$ & 16.6 & 3.9 & $<0.001$ \\
January $d T$ & 3.1 & 3.2 & $>0.20$ \\
January $T$ & 0.8 & 0.1 & $<0.001$ \\
January $D$ & 0.0 & 0.0 & NA \\
January $U$ & 14.9 & 13.4 & 0.20 \\
April $C$ & 52.0 & 46.0 & 0.05 \\
April $P a$ & 15.2 & 6.2 & $<0.001$ \\
April $d T$ & 6.9 & 13.0 & $<0.001$ \\
April $T$ & 5.9 & 8.4 & 0.05 \\
April $D$ & 0.5 & 0.0 & NA \\
April $U$ & 19.6 & 26.4 & $<0.001$ \\
July Po & 33.5 & 10.8 & $<0.001$ \\
July $T$ & 25.3 & 56.2 & $<0.001$ \\
July $D$ & 12.6 & 9.2 & 0.05 \\
July $U$ & 28.5 & 23.8 & $<0.001$ \\
October $C$ & 34.7 & 40.6 & 0.05 \\
October $P a$ & 26.9 & 14.5 & $<0.001$ \\
October $d T$ & 7.9 & 9.6 & 0.10 \\
October $T$ & 5.5 & 3.8 & 0.02 \\
October $D$ & 1.3 & 0.0 & NA \\
October $U$ & 23.8 & 31.5 & $<0.001$ \\
& & & \\
\hline
\end{tabular}

cially in the southwest portion of the NCUS, at the expense of the other 3 air masses. $D$ air was closer to the correct magnitude and was significantly similar to the observed spatial distribution (Table 2, Fig. 5). GCM temperatures were dissimilar from observed temperatures for all air mass types (Table 3). Dew point values were similar for $D$ air, but significantly different from observed for all other types.

\subsection{October}

As in July, the October spatial patterns for the observed and GCM cases were fairly similar for most air masses, with some noted differences in magnitude (Tables 1 \& 2). Within the GCM, $C$ air frequency was somewhat high, especially in the north and northeast portions of the study area. The GCM $C$ pattern was also slightly different, being characterized by a southwest-to-northeast orientation, as compared to the more north-south orientation of the observed data (Table 1). $P a$ air was spatially similar between the 2 cases, but magnitudes varied considerably, as GCM

magnitude there were notable differences between the GCM and observed values (Table 2). $T$ air was vastly overrepresented in the GCM scenario, espe- values became progressively too low in the eastern study area (Fig. 6). Both $d T$ and $T$ air GCM distributions were centered in the southwestern NCUS, while

Table 3. Air mass temperature and dew point comparison. Obs.: observed. Other abbreviations given in Table 1

\begin{tabular}{|c|c|c|c|c|c|c|c|}
\hline $\begin{array}{l}\text { Air mass } \\
\text { type }\end{array}$ & $\begin{array}{c}\text { Obs. average } \\
850 \mathrm{hPa} \\
\text { temp. }\left({ }^{\circ} \mathrm{C}\right)\end{array}$ & $\begin{array}{c}\text { GCM average } \\
850 \mathrm{hPa} \\
\text { temp. }\left({ }^{\circ} \mathrm{C}\right)\end{array}$ & $\begin{array}{l}\text { Sig. level of } \\
850 \mathrm{hPa} \\
\text { temp. } t \text {-test }\end{array}$ & $\begin{array}{l}\text { Obs. average } \\
850 \mathrm{hPa} \\
\text { dew point }\left({ }^{\circ} \mathrm{C}\right)\end{array}$ & $\begin{array}{l}\text { GCM average } \\
850 \mathrm{hPa} \\
\text { dew point }\left({ }^{\circ} \mathrm{C}\right)\end{array}$ & $\begin{array}{c}\text { Sig. level of } \\
850 \mathrm{hPa} \\
\text { dew point } t \text {-test }\end{array}$ & $\begin{array}{c}\text { No. cases } \\
850 \mathrm{hPa} \\
\text { Obs./GCM }\end{array}$ \\
\hline January $C$ & -9.5 & -9.1 & 0.20 & -15.4 & -14.1 & $<0.001$ & $1571 / 282$ \\
\hline January $P a$ & 4.4 & 3.0 & $<0.001$ & -9.4 & -6.9 & $<0.001$ & $1042 / 75$ \\
\hline January $d T$ & 4.0 & 4.4 & $>0.20$ & 1.1 & 1.3 & $>0.20$ & $279 / 64$ \\
\hline January $T$ & NA & $\mathrm{NA}$ & NA & NA & NA & NA & NA \\
\hline January $D$ & NA & NA & NA & NA & $\mathrm{NA}$ & NA & NA \\
\hline January $U$ & 0.0 & 0.1 & $>0.20$ & -8.3 & -6.0 & $<0.001$ & $1232 / 245$ \\
\hline April C & -1.6 & -0.7 & $<0.001$ & -8.6 & -5.2 & $<0.001$ & $1597 / 286$ \\
\hline April $\mathrm{Pa}$ & 9.4 & 8.2 & $<0.001$ & -4.6 & -0.1 & $<0.001$ & $1163 / 112$ \\
\hline April $d T$ & 9.6 & 8.7 & $<0.001$ & 5.7 & 5.9 & 0.20 & $584 / 230$ \\
\hline April $T$ & 12.3 & 11.3 & $<0.001$ & 9.7 & 9.3 & 0.10 & $457 / 124$ \\
\hline April D & NA & $\mathrm{NA}$ & NA & $\mathrm{NA}$ & NA & NA & NA \\
\hline April $U$ & 6.6 & 5.6 & $<0.001$ & -2.6 & 1.2 & $<0.001$ & $1472 / 426$ \\
\hline July $P_{0}$ & 11.6 & 13.0 & $<0.001$ & 3.3 & 4.8 & $<0.001$ & $1520 / 158$ \\
\hline July $T$ & 18.0 & 20.3 & $<0.001$ & 14.2 & 14.8 & $<0.001$ & $1457 / 354$ \\
\hline July $D$ & 21.8 & 22.7 & $<0.001$ & 7.1 & 7.4 & 0.20 & $818 / 129$ \\
\hline July $U$ & 16.6 & 18.7 & $<0.001$ & 8.6 & 9.8 & $<0.001$ & $2042 / 433$ \\
\hline October $C$ & -1.1 & -0.3 & $<0.001$ & -7.4 & -4.0 & $<0.001$ & $1446 / 328$ \\
\hline October $\mathrm{Pa}$ & 9.8 & 8.2 & $<0.001$ & -3.6 & 0.9 & $<0.001$ & $1768 / 236$ \\
\hline October $d T$ & 11.0 & 10.3 & $<0.001$ & 7.6 & 7.5 & $>0.20$ & $700 / 182$ \\
\hline October $T$ & 15.7 & 13.6 & $<0.001$ & 13.4 & 11.8 & $<0.001$ & $455 / 65$ \\
\hline October $D$ & NA & NA & NA & NA & NA & NA & NA \\
\hline October $U$ & 7.8 & 6.1 & $<0.001$ & -1.7 & 1.7 & $<0.001$ & $1856 / 531$ \\
\hline
\end{tabular}




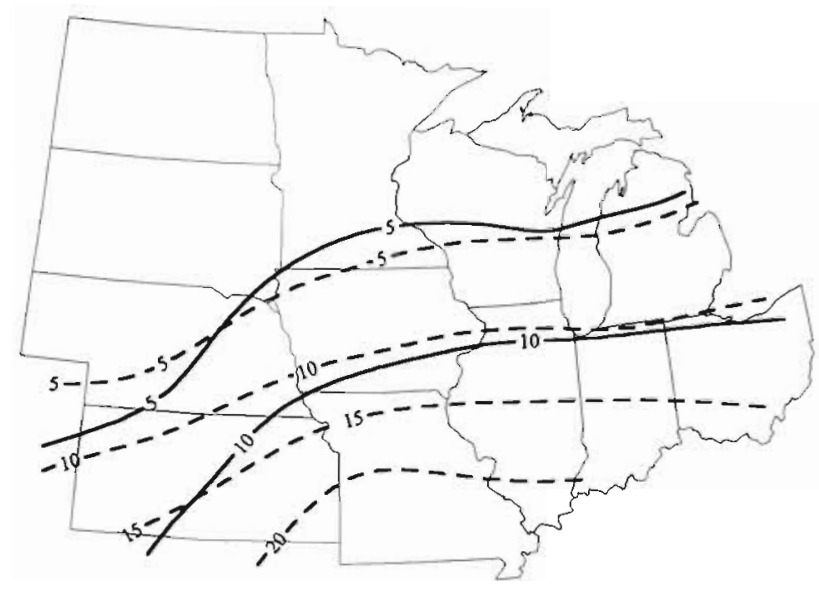

Fig. 4. April Tropical air mass relative frequency comparison in the NCUS between observed data (solid lines) and GENESIS GCM-derived data (dashed lines)

the highest observed values occurred in the south central portion of the study area. Relative GCM frequency values were not significantly different for $d T$ air, but too low for $T$ air (Table 2). The $U$ air pattern and magnitude in the GCM and observed situations were both quite different. As in April, $D$ air was not frequent enough in this month to be effectively compared. Air mass temperatures were significantly different between the observed and GCM values for all types (Table 3). With the exception of $d T$ air, GCM and observed air mass dew points were also dissimilar.

\section{DISCUSSION AND CONCLUSIONS}

The surface-circulation connection at the heart of synoptic climatology facilitates its application to

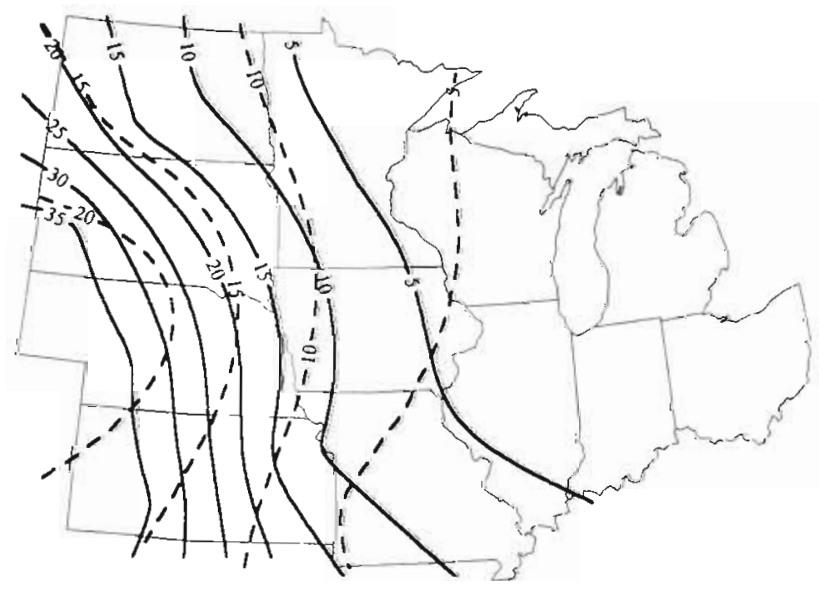

Fig. 5. July Dry Tropical air mass relative frequency comparison in the NCUS between observed data (solid lines) and GENESIS GCM-derived data (dashed lines)

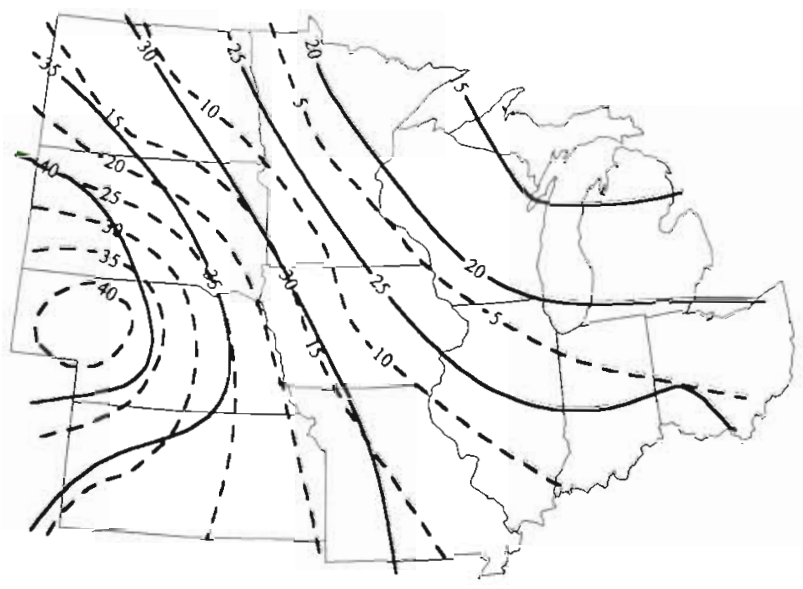

Fig. 6. October Pacific air mass relative frequency comparison in the NCUS between observed data (solid lines) and GENESIS GCM-derived data (dashed lines)

diagnosing regional GCM performance. When GCM control-run simulations are evaluated, daily output variables are often averaged by month and compared to observed data. This approach ignores the multimodal characteristic of mid-latitude climate (Schwartz 1995). Differences between monthly means from placeto-place or year-to-year are not typically the result of all days in a month being equally modified. Instead, changes in the frequencies of sub-groups of days with characteristic ranges of temperature and moisture values (air masses) are more often the cause. The following discussion is based on the premise that nearsurface air mass distributions can give indications of the overlying $500 \mathrm{hPa}$ flow patterns and that the NCUS is a key area for observing changes representative of continent-wide processes, as demonstrated in Schwartz \& Skeeter (1994).

One prominent season-wide feature confirmed by this observed-GCM comparison was overly high dew points for most air mass types within the GENESIS GCM simulation. This result was expected, as Thompson \& Pollard (1995) note that the GCM places too much low-level moisture in higher latitudes. The correspondence of GCM results to observed data is slightly different for each season.

In January, the $C$ air distribution across the NCUS implies that the GCM is correctly reproducing the modal $500 \mathrm{hPa}$ ridge-trough (PNA) pattern of North America, resulting in frequent occurrences of cold continental $C$ air across the NCUS. However, the GCM overestimates the dominance of this air mass. Thompson \& Pollard (1995) suggest that the GCM is too cold in winter because of over-simulated cloud cover. Yet, temperatures of $C$ and $d T$ air were not significantly different from the observed data, indicating that the overall GCM north-south thermal gradient is generally 
accurate. Missing from the simulation, though, is the appropriate number of other patterns, such as zonal flow (connected with $P a$ air, and central or western troughs) tied to $d T$ and $T$ air intrusions. These overall results also suggest that the GENESIS control-run winter simulation is somehow different from its progenitor, the Community Climate Model (CCM) GCM (Appendix 2). Mearns et al. (1990) reported warmerthan-observed temperatures in the Great Plains and cooler-than-observed temperatures in the Great Lakes region during the cold season within the GCM simulation.

Based on the GENESIS GCM January air mass patterns, one might conclude that the GCM physics are too simplistic to pick up lower frequency synoptic events. The spring GCM pattern demonstrates that the answer is not that simple. In April, the GCM simulation comes quite close to accurately reproducing the range of air mass types - and thus the overlying $500 \mathrm{hPa}$ flow patterns - across the NCUS. Now, however, GCM air mass temperatures are not accurate. $C$ air is too warm, and all other air masses are too cold. Thus the northsouth thermal gradient may be too low in the GCM, suggesting the simulation might underrepresent midlatitude general circulation energetics.

The summer GENESIS GCM simulation is too extreme in several regards. Temperatures for all air masses are too warm, and there is an excess of $T$ air across the entire NCUS. Thompson \& Pollard (1995) attribute the excess warmth to inadequate cloud cover. While the spatial patterns associated with the different air mass types appear correct, the implication is that as in winter, the GCM simulation is 'overstating' the dominant air mass type (in this case $T$ air). In contrast to winter, however, the thermal gradient appears to also be underestimated by the GCM. This implies a sluggish simulation of the mid-latitude general circulation, i.e. more energy-depleted than actually occurs in the summer. As in winter, the summer GENESIS simulation appears different from the CCM control run, where temperatures were either near-observed or cooler-than-observed in the Great Plains and warmerthan-observed in the Great Lakes region (Mearns et al. 1990).

The autumn GCM simulation resembles spring, in that the north-south thermal gradient may be underrepresented. $C$ air is warmer and other air masses colder than observed data values. Unlike spring (and reminiscent of winter) the relative frequency of $C$ in the GCM simulation is a bit high, at the expense of the other air mass types. This supports a less-energeticthan-observed mid-latitude general circulation in the autumn GCM simulation, incorporating more continent-wide $500 \mathrm{hPa}$ ridge-trough occurrences (associated with $C$ air than actually occur.
In conclusion, the air mass results suggest that the GCM simulation fares much better in recreating a proper mix of synoptic patterns in seasons where 1 type is not overwhelmingly dominant. The GCM tends to overemphasize the prominence of $C$ air in winter, and $T$ air in summer, coming much closer to the proper distribution of types in the spring and autumn seasons. As to the spatial patterns themselves, the evidence suggests that these are simulated rather well in most cases by the GENESIS GCM, particularly in light of the coarse resolution of the simulation. Differences are found more in pattern frequency, rather than the patterns themselves. Finally, dew points are universally too high, and air mass temperatures are not well represented in the nonwinter seasons. Cold air masses tend to be too warm, and warm air masses too cold in spring and autumn. In summer, all air masses are too warm. While the overall GCM performance in the NCUS is promising, these results suggest that there may be substantial differences between the GENESIS GCM control run and observed climate data at the daily time scale. Thus, caution should be exercised in generating daily weather elements from GCM control-run information. Given these uncertainties in the current climate simulation, a projection of daily synoptic frequencies in $2 \times \mathrm{CO}_{2}$ simulations may be premature at this point.

Acknowledgements. I thank Abraham Oort for the upper-air statistical data he kindly provided, and Dave Pollard for supplying me with the GENESIS grid point data which made this study possible.

\section{LITERATURE CITED}

Brinkmann WAR (1993) Development of an airmass-based regional climate change scenario. Theor Appl Climatol 47:129-136

Bryson RA (1966) Air masses, streamlines, and the Boreal Forest. Geogr Bull 8:228-269

Dickinson RE, Henderson-Sellers A, Kennedy PJ, Watson MF (1986) Biosphere-Atmosphere Transfer Scheme (BATS) for the NCAR Community Climate Model. NCAR Tech Note NCAR/TN-275+STR, Boulder, CO

Dorman JL, Sellers PJ (1989) A global climatology of albedo, roughness length, and stomatal resistance for atmospheric general circulation models as represented by the Simple Biosphere Model (SiB). J Appl Meteorol 28:833-855

Frakes B, Yarnal B (1995) The variable response of watersheds to synoptic forcing: the SRBEX results. Conference preprints, Sixth symposium on global change studies. American Meteorological Society, Boston, MA, p 62-66

Grotch SL, MacCracken MC (1991) The use of general circulation models to predict regional climate change. J Clim 4:286-303

Hewitson B (1994) Regional climates in the GISS General Circulation Model: surface air temperature. J Clim 7:283-303

Hewitson B, Crane RG (1992) Regional climates in the GISS Global Circulation Model: synoptic-scale circulation. J Clim 5:1002-1011 
Kalkstein LS, Dunne PC, Vose RS (1990) Detection of climatic change in the western North American Arctic using a synoptic climatological approach. J Clim 3:1153-1167

Legates DR, Willmott CJ (1990a) Mean seasonal and spatial variability in gauge-corrected, global precipitation. Int J Climatol 10:111-127

Legates DR, Willmott CJ (1990b) Mean seasonal and spatial variability in global surface air temperature. Theor Appl Climatol 41:11-21

Mearns LO, Schneider SH, Thompson SL, MCDaniel LR (1990) Analysis of climate variability in general circulation models: comparison with observations and changes in variability in $2 \times \mathrm{CO}_{2}$ experiments. J Geophys Res 95(D12): $20469-20490$

Schlatter TW, Baker DV (1981) Algorithms for thermodynamic calculations. NOAA/ERL PROFS Program Office Boulder, $\mathrm{CO}$

Schlesinger ME, Mitchell JFB (1987) Climate model simulations of the equilibrium climatic response to increased carbon dioxide. Rev Geophys 25:760-798

Schneider SH, Rosenberg NJ (1989) The Greenhouse Effect: its causes, possible impacts, and associated uncertainties. In: Rosenberg NJ, Easterling WE III, Crosson PR, Darmstadter J (eds) Greenhouse warming: abatement and adaptation. Resources for the future, Washington, DC, p $7-34$

Schwartz MD (1991) An integrated approach to air mass classification in. the North Central United States. Prof Geog 43:77-91

Schwartz MD (1995) Detecting structural climate change: an air mass-based approach in the North Central United States, 1958-1992. Ann Ass Am Geogr 85:553-568

Schwartz MD, Harman JR, Marotz GA (1985) Air mass characteristics over the North Central United States. Geogr Perspect 56:13-26

Schwartz MD, Skeeter BR (1994) Linking air mass analysis to daily and monthly mid-tropospheric flow patterns. Int $J$ Climatol 14:439-464

Sellers PJ, Mintz Y, Sud YC, Dalcher A (1986) A simple biosphere model $(\mathrm{SiB})$ for use within general circulation models. J Atmos Sci 43:505-531

Shea D (1986) Climatological atlas: 1950-1979. Surface-air temperature, precipitation, sea-level pressure, and seasurface temperature. NCAR Tech Note NCAR/TN. 269TSTR, Boulder, CO

Thompson SL, Pollard D (1995) A global climate model (GENESIS) with a land-surface-transfer scheme (LSX). Part 1, Present climate simulation. J Clim 8:732-761

Appendix 1. The Integrated Method Air Mass Classification Scheme

Schwartz (1991) determined numerical $850 \mathrm{hPa}$ air mass temperature and dew point criteria for the NCUS (Fig. 2) using a 3 -stage approach. In the first (manual) stage, at each station, a trajectory analysis was conducted. This identified the range of $850 \mathrm{hPa}$ temperature and dew point values associated with major air mass types in each of the 4 seasons. The technique involves tracking air masses at the $850 \mathrm{hPa}$ level from known source regions as they move into and through the study area. The correspondences of observed $850 \mathrm{hPa}$ dew point ranges to surface values were also determined by relating them to surface dew point limits previously identified in Schwartz et al. (1985).

Here is an example of the trajectory analysis procedure. In establishing the upper Continental air (equivalent to traditional continental Polar air) temperature limit in January, Continental. air masses over their central Canadian source region were identified. Temperatures associated with wind shifts and other discontinuities-roughly equivalent to fronts, the traditional definition of the boundary between dissimilar air masses - in the $850 \mathrm{hPa}$ surface were then recorded as the air masses moved into and through the study area. Observation of many such passages provided confidence that the specific definitions for each air mass type were accurate. This procedure produced initial numerical limits and transition zones for the Polar (Po, a mixture of traditional continental Polar and maritime Polar air), Tropical ( $T$, equivalent to traditional maritime Tropical air), and Dry Tropical (D, equivalent to traditional continental Tropical air) air masses in summer In other seasons, Continental ( $C$, equivalent to traditional continental Polar air), Pacific ( $P a$, equivalent to traditional maritime Polar air), dilute Tropical ( $d T$, a 'dilute' form of traditional maritime Tropical air), $T$, and $D$ air masses were identified. The $d T$ and $T$ air masses were determined by using only $850 \mathrm{hPa}$ dew point tempera- ture. Days with either the $850 \mathrm{hPa}$ temperature or $850 \mathrm{hPa}$ dew point falling in a transition zone were placed in the $U$ category. All other air masses were defined by both $850 \mathrm{hPa}$ temperature and $850 \mathrm{hPa}$ dew point criteria (Fig. 2).

The automated stage of the technique used the partial collective method proposed by Bryson (1966). This approach assumes that the daily temperature or dew point frequency distribution at a station is composed of a mixture of normal curves, each representing the real range of values associated with a different air mass type (Bryson 1966). The procedure then provides best estimates of the mean, standard deviation, and weight (i.e. percent of the total distribution) for each of these component normal curves by iteration. Initial starting values are supplied by the researcher. In this fashion, the statistical characteristics of every air mass type's temperature and moisture values (tied to a normal curve) were found at each station during the 4 seasons. The last stage coordinated the manual and automated results. Final transition zones (values between air mass numerical limits) contained the temperature or dew point value where adjacent air mass-related normal curve component distributions crossed (i.e. had the same $Z$-score probability). These zones represent areas of air mass mixing, and were arbitrarily standardized to all be $3^{\circ} \mathrm{C}$ wide. One major advantage of the integrated method approach is that although temperature and moisture limits define the air masses, geographic information inherent in classical manual schemes remains. Thus, air masses-derived in part from trajectory analysis - can be identified as clearly coming from a particular source region. This simplifies the interpretation of spatial patterns (Schwartz \& Skeeter 1994). Another advantage is that $Z$-scores from the normal curves, and the relative frequency of $U$ days, can estimate potential misclassification error at any location. 
Appendix 2. GENESIS Global Climate Model Version 1.02

A brief outline of the GENESIS GCM is provided here Thompson \& Pollard (1995) present a full description of the model implementation and error analysis for a present climate simulation. Version 1.02 of the GENESIS Global Climate Model includes an Atmospheric General Circulation Model (AGCM), a land-surface transfer model (LSX). a soil model, a thermodynamic snow model, a thermodynamic sea ice model, and an ocean model.

Model components. The AGCM originated from the NCAR Community Climate Model (CCM) Version 1, which uses the spectral transformation method in the horizontal for mass, heat, and momentum. A $\sigma$-coordinate system is used in the vertical with 12 levels from $\sigma=0.991$ up to 0.009 . Modifications to the original CCM code include addition of a diurnal cycle, water vapor advection in grid space by semi-Lagrangian transport, convection in the atmosphere using an explicit subgrid plume model, and 3 possible cloud types: stratus, anvil cirrus, and convective. The AGCM horizontal grid is independent of the surface grid. Fields are transferred between the AGCM and the surface by bilinear interpolation (AGCM-tosurface) or straightforward area-averaging (surface-toAGCM) at each timestep. The AGCM has a horizontal spectral resolution of $\mathrm{R} 15$ (with a transform grid $\sim 4.5^{\circ}$ ]at. $\times 7.5^{\circ}$ long.). The surface resolution used by the vegetation, soil, snow, sea ice, and ocean models is $2^{\circ} \times 2^{\circ}$, with the Great Lakes represented by 2 grid points of $50 \mathrm{~m}$ 'ocean' (see below)

The LSX land-surface model accounts for the physical effects of vegetation. LSX is based on the earlier BATS (Dickinson et al. 1986) and SiB (Sellers et al. 1986) models and is intermediate in complexity between the two. Two vegetation layers ('trees' and 'grass') can be specified at each grid point, and the radiative and turbulent fluxes through these layers to the soil or snow surface are calculated. Vegetation attributes such as leaf area indices, fractional cover, and leaf albedo are taken from the Dorman \& Sellers (1989) global data set. A 6-layer soil model extends from the surface to a depth of $4.25 \mathrm{~m}$. Heat is diffused linearly, and soil moisture is diffused highly nonlinearly. Surface runoff occurs if the precipitation minus evaporation exceeds the maximum possible infiltration rate

A 3-layer thermodynamic snow model is used for snowcover on soil, ice sheet, and sea ice surfaces, including fractional areal cover when the snow is thin. Heat is diffused linearly through the snow, and the total thickness changes due to melting or snowfall on the upper layer. A 6-layer thermodynamic ice model predicts the local melting and freezing of ice. Heat diffuses linearly through the ice, and the total thickness can change by melting or freezing. In all simulations with ice dynamics, both the surface wind and ocean current fields were prescribed rather than obtained from the AGCM, due to the poor modeling of these fields in the Arctic.
The ocean is represented by a $50 \mathrm{~m}$ thick thermodynamic slab, which crudely captures the seasonal heat capacity of the ocean mixed layer. Poleward oceanic heat transport is prescribed as a zonally symmetric function of latitude based on present-day observations. Thompson \& Pollard (1995) emphasize that the oceanic heat flux is based only on observations and can truly reflect errors in AGCM surface fluxes. This reduces the constraints imposed by observed sea surface temperatures used in many recent coupled GCMs

Model performance. Thompson \& Pollard (1995) compared atmospheric cross sections to European Centre for Medium Range Weather Forecasting global analyses averaged over the 1985-1989 period. There was relatively good agreement between the model control run and the observations in most of the lower troposphere below $500 \mathrm{hPa}$; however, large cold biases were present in the upper troposphere and stratosphere (as in NCAR CCM1 model runs). The general realism of the GENESIS lapse rates below $500 \mathrm{hPa}$ is a considerable improvement over the CCM1 model, which had a strong cold bias throughout most of the troposphere. Regarding relative humidity, too moist values in polar regions suggest that the model is overstating the latitudinal transport of water vapor, at least in July.

Surface air temperature and precipitation fields were compared to observed data compiled by Legates \& Willmott $(1990 \mathrm{a}, \mathrm{b})$. The model tends to be too warm over land at latitudes above $60^{\circ} \mathrm{N}$. This error is apparently caused by deficiencies in the model's cloudiness, with warm errors associated with too little cloudiness in summer and too much in winter. Broad-scale precipitation patterns are simulated correctly, including the seasonal movement of the Inter-Tropical Convergence Zone, the dry subtropics, and the relative dryness of northern continents. However, the overall precipitation magnitude is about $50 \%$ larger than observed.

GENESIS sea level pressure maps were compared to the observed data set of Shea (1986). The amplitude and locations of most features are generally correct, including the oceanic subtropical highs, the Aleutian and Icelandic lows in January, and the continental winter highs and summer lows. Exceptions include the location of the Icelandic low in January, which is too far south, and the ridge over western Canada, which is too weak.

Thompson \& Pollard (1995) conclude that the presentday performance of the model is similar to previous coarse-grid AGCMs with predicted Sea-Surface Temperatures, producing regional errors in monthly surface-air temperatures of $-5^{\circ} \mathrm{C}$ or less in most regions'. Noted surface errors include too warm surface temperatures over high latitude Northern Hemisphere land in summer due to too little cloudiness, and an over-estimation of global precipitation related to a too large prescribed value of aerodynamic roughness over the ocean. 